\title{
Ovariossalpingo-histerectomia em cadelas: comparação da dor e análises cardiorrespiratória, pressórica e hemogasométrica nas abordagens convencional, por NOTES híbrida e NOTES total
}

\author{
[Ovariosalpingohisterectomy in bitches: comparison of pain, cardiopulmonary, pressure \\ and arterial blood gas analysis of the conventional approaches, by \\ NOTES hybrid and NOTES pure]
}

\author{
P.C. Basso', A.G. Raiser ${ }^{2}$, M.V. Brun ${ }^{2}$, D.C.M. Müller ${ }^{3 *}$, R. Lukarsewski ${ }^{4}$, G.M.C. Serafini ${ }^{1}$, \\ G.C. Freitas ${ }^{5}$, L.H. Dutra ${ }^{6}$, F. Marconato ${ }^{1}$ \\ ${ }^{1}$ Hospital Veterinário - Universidade Federal de Santa Maria -UFSM - Santa Maria, RS \\ 2 Programa de pós-graduação - UFSM - Santa Maria, RS \\ ${ }^{3}$ Programa de pós-graduação - Universidade Regional do Noroeste do Estado do Rio Grande do Sul - Ijuí, RS \\ ${ }^{4}$ Hospital Veterinário - Universidade Regional do Noroeste do Estado do Rio Grande do Sul - Ijuí, RS \\ ${ }^{5}$ Universidade Federal Fronteira Sul - Realeza, PR \\ ${ }^{6}$ Programa de Residência - UFSM - Santa Maria, RS.
}

\begin{abstract}
RESUMO
A cirurgia endoscópica por orifícios naturais (NOTES) é um novo conceito de abordagem videocirúrgica, que surge como alternativa à cirurgia convencional, eliminando incisões abdominais e as possíveis complicações relacionadas a ela. A proposta deste artigo foi comparar técnicas de ovariossalpingohisterectomia $(\mathrm{OSH})$ em cadelas, buscando determinar o procedimento que oferece menores alterações hemodinâmicas e menos estímulos dolorosos trans e pós-operatório. Para tanto, foram utilizadas 21 cadelas alocadas em três grupos. No primeiro, os pacientes foram submetidos à OSH por celiotomia (GC), no segundo por meio da técnica de NOTES híbrida (GNH) e no terceiro (GNT), utilizando-se a técnica de NOTES total. O tempo cirúrgico do GNH foi significativamente maior que nos demais grupos. Em ambos os grupos de cirurgia NOTES, verificou-se diminuição das pressões arteriais médias e diastólicas no transoperatório. Apenas o grupo GNH desenvolveu acidose severa no transoperatório. Levando-se em consideração as avaliações da dor, apenas o grupo convencional necessitou de analgesia resgate transcirúrgica. No pós-operatório, observou-se que os cães do GC apresentaram índices mais elevados na escala visual analógica e na escala de Melbourne que os animais dos demais grupos, sendo necessária analgesia resgate em $100 \%$ deles. Em contraste, no GNT nenhum dos cães requereram complementação analgésica pós-operatória. Conclui-se que a técnica de OSH por NOTES total apresenta parâmetros cardiorrespiratórios e hemogasométricos semelhantes à técnica convencional e mais estáveis que a técnica de NOTES híbrida, bem como resulta em menor dor trans e pós-operatória que a técnica convencional.
\end{abstract}

Palavras-chave: cão, cirurgia endoluminal, cirurgia sem incisão, videocirurgia

\begin{abstract}
The aim of the present study was to perform bacteriological and molecular methods for identification of Mycobacterium bovis in lesions derived from bovine carcasses detected during routine post-mortem examination in officially inspected slaughterhouses. We checked the slaughter and inspection of 825,394 bovines, health upon ante-mortem examination, by the official service in 10 slaughterhouses of Bahia state from April, 2009 to April 2012. Lesions suggestive of tuberculosis were collected from 180 bovines
\end{abstract}

Recebido em 20 de março de 2013

Aceito em 18 de dezembro de 2013

*Autor para correspondência (corresponding author)

E-mail: cmdaniel@terra.com.br 
and further evaluated by bacteriology and multiplex PCR. The majority of lesions were located in the respiratory tract lymph nodes and $71 \%$ were from male bovines up to 32 months old. $13.9 \%$ of samples presented small, granular and creamy-yellowish colonies after being cultured in Stonebrink-Leslie with an average growth time of 34 days. All smears from the isolated samples were Acid Fast Bacilli (AFB) and among them 56\% were identified by $\mathrm{mPCR}$ as M. bovis. Thus, the association between post-mortem examination, culture and multiplex PCR allowed the bacillus identification in a reduced time and in regions of low prevalence, pointing out its importance for bovine tuberculosis detection and as a supportive tool for the tuberculosis control and eradication program.

Keywords: dog, endoluminal surgery, incisionless surgery, videosurgery

\section{INTRODUÇÃO}

A minimização da dor no período de recuperação pós-operatória e das possíveis complicações no trans-operatório constitui uma das principais preocupações dos cirurgiões veterinários. Por isso, muitos avanços se desenvolveram em torno da criação de novas técnicas e procedimentos operatórios que buscam reduzir o trauma tecidual, os processos inflamatórios, os riscos cirúrgicos, a dor do paciente e as cicatrizes indesejáveis (Otero, 2005). Dentro do conceito de redução do trauma operatório, técnicas videocirúrgicas alternativas, que objetivam o mínimo trauma tecidual, estão sendo desenvolvidas, e atenção especial tem sido dada à laparoendoscopic single site surgery (LESS) e à cirurgia endoscópica por orifícios naturais (NOTES). Ao utilizarem essa última modalidade, os cirurgiões podem acessar a cavidade abdominal através da parede gástrica, colônica ou vaginal, realizar o procedimento e finalizar com o fechamento do defeito visceral criado para o acesso cirúrgico (Shafi et al., 2006).

Wagg et al. (2006) descrevem como vantagens potenciais na aplicação da NOTES o fato de se operar com menores graus de invasão e traumatismo abdominal, assim como de haver queda significativa de infecção hospitalar e do tempo de convalescença. Verifica-se também a realização de cirurgias sem cicatriz (Kalloo et $a l ., 2004)$ e com menores riscos de infecções e herniações (Bergman e Melvin, 2008).

A técnica de ovariossalpingo-histerectomia (OSH) eletiva é o procedimento videocirúrgico mais realizado na medicina veterinária, sendo viáveis na modalidade de NOTES dois acessos, denominados NOTES híbrida (Brun et al., 2011) e NOTES total (Silva et al., 2010). Ainda que essas técnicas já tenham sido descritas, fazem-se necessárias pesquisas aprofundadas que visem compará-las tanto no caráter hemodinâmico quanto no álgico, para, então, definir qual abordagem é mais segura e menos invasiva ao paciente.

Considerando a importância que a NOTES vem demonstrando na cirurgia experimental e seu potencial real de aplicação e desenvolvimento na rotina cirúrgica de humanos e dos demais animais, este artigo teve o objetivo de comparar duas técnicas de OSH envolvendo NOTES com a técnica convencional, a fim de determinar o procedimento que oferece menores alterações cardiorrespiratórias, pressóricas, gasométricas e menos estímulos dolorosos nos períodos trans e pós-operatório de cadelas.

\section{MATERIAL E MÉTODOS}

O experimento foi aprovado pelo Comitê de Ética no Uso de Animais (CEUA) da UFSM, sob o registro 015/2011. Para análise dos resultados, foram utilizadas 21 cadelas, adultas, pesando entre $7,5-21,3 \mathrm{~kg}(14,85 \pm 3,75 \mathrm{~kg})$, as quais foram incluídas no estudo após serem consideradas hígidas por meio de exame clínico e laboratorial. Os animais foram mantidos em gaiolas por um período de três dias para adaptação ao ambiente experimental e ao contato com os observadores antes do experimento. A amostra foi separada em três grupos de sete cães. No primeiro, denominado GC, os pacientes foram submetidos à técnica de $\mathrm{OSH}$ por celiotomia retroumbilical. No segundo grupo (GNH), a OSH foi efetuada por meio da técnica de NOTES híbrida. E no terceiro grupo (GNT), as cadelas foram submetidos à OSH utilizando-se a técnica de NOTES total.

Após jejum sólido de 12 horas, as cadelas foram induzidas à anestesia geral por meio de vaporização de isoflurano em máscara facial, em máxima concentração. Posteriormente, realizou- 
se a punção da artéria podal dorsal utilizando-se cateter $22 \mathrm{G}$ para mensuração invasiva das pressões arteriais sistólica (PAS), média (PAM) e diastólica (PAD) em monitor multiparamétrico. Nesse momento, também se procedeu à canulação da veia jugular com cateter 20G, conectado a um transdutor de pressão e monitor multiparamétrico, para mensuração da pressão venosa central (PVC). Em seguida, foi aguardada a completa recuperação dos animais. Quarenta e cinco minutos após a recuperação anestésica, foram aferidas frequência cardíaca (FC), frequência respiratória $(f)$, PAS, PAM, PAD, PVC e temperatura retal; tais valores foram considerados como basais. Em seguida, foi realizada a coleta de sangue arterial para gasometria. Por conseguinte, os animais foram pré-medicados com acepromazina $(0,05 \mathrm{mg} / \mathrm{kg}$, IM), tramadol (4mg/kg, IM) e cetamina $(0,5 \mathrm{mg} / \mathrm{kg})$ e instituiu-se fluidoterapia com solução fisiológica na velocidade de $10 \mathrm{~mL} / \mathrm{kg} /$ hora. Quinze minutos após a aplicação da medicação pré-anestésica, os parâmetros foram novamente mensurados e, posteriormente, realizaram-se a indução anestésica com propofol $(4 \mathrm{mg} / \mathrm{kg}, \mathrm{IV})$ e a manutenção anestésica com isoflurano (1CAM) vaporizado em oxigênio a $100 \%$. Instituiu-se profilaxia antibacteriana com ampicilina sódica $(20 \mathrm{mg} / \mathrm{kg}, \mathrm{IV})$. Durante o procedimento cirúrgico, os animais foram submetidos à ventilação controlada, mantendo-se a concentração expirada de $\mathrm{CO}_{2}\left(\mathrm{ETCO}_{2}\right)$ entre $35-45 \mathrm{mmHg}$. Para isso, realizou-se bloqueio neuromuscular com besilato de atracúrio $(0,2 \mathrm{mg} / \mathrm{kg})$, e a $f$ foi ajustada conforme a necessidade. Naqueles pacientes em que a PAS e a FC demonstraram elevação acima de $20 \%$ do valor basal, foi instituída analgesia resgate no transoperatório com sulfato de fentanil $(5 \mathrm{ug} / \mathrm{kg}$, IV).

Para a OSH por celiotomia (grupo GC), realizouse incisão da região retroumbilical, sobre a linha média, de aproximadamente $5 \mathrm{~cm}$ de comprimento, desde a pele até a abertura da cavidade abdominal. Foram identificados os ovários e ambos foram extraídos após triplo pinçamento modificado e ligadura circular e transfixante com ácido poliglicólico 2-0. O corpo do útero foi triplamente pinçado, seccionado e ligado com mesmo fio, aplicando-se uma ligadura transfixante. A cavidade abdominal foi obliterada mediante sutura de Sultan com ácido poliglicólico 2-0, seguida de redução do espaço morto com sutura contínua com fio de mesma natureza 3-0, e encerrada com sutura da pele com fio monofilamentar de náilon 4-0, em padrão isolado simples.

Já para a OSH por NOTES híbrida (grupo GNH), realizou-se antissepsia do abdômen, da vulva e do períneo. A vagina foi higienizada com iodo polivinil-pirrolidona (PVP-I) a $0,1 \%(10 \mathrm{~mL} / \mathrm{kg})$, seguindo-se com a aplicação de sonda uretral n.8 de forma asséptica. Com o emprego da agulha de Verres, promoveu-se a insuflação da cavidade abdominal com dióxido de carbono $\left(\mathrm{CO}_{2}\right)$ até a pressão de $12 \mathrm{mmHg}$. Pela técnica aberta, foi introduzido um artroscópio de $2,7 \mathrm{~mm}$ na região da cicatriz umbilical, permitindo a visualização do abdômen.

O segundo portal (10mm) foi introduzido caudoventralmente à cérvix, sob visualização da óptica, evitando-se, dessa forma, possíveis lesões viscerais. $\mathrm{Na}$ sequência, os pacientes foram posicionados em decúbito lateral direito conforme descrito por Silva (2008) para a hemostasia do mesovário esquerdo. $\mathrm{O}$ ovário foi identificado, e a mesossalpinge apreendida para fixação temporária desse órgão à parede abdominal lateral esquerda por meio de sutura transparietal reparada externamente à cavidade. O mesovário e o ligamento suspensor foram cauterizados e seccionados com pinça bipolar munida com lâmina de corte. Em seguida, a sutura transparietal foi liberada, e o animal posicionado para o acesso do ovário direito. Após a secção e a cauterização do mesovário direito, este foi apreendido e tracionado em direção à vagina até o interior da cânula e retirado pela ferida vaginal, juntamente com o corno uterino direito. Por conseguinte, foram expostos o corno uterino esquerdo, o ovário esquerdo e o corpo do útero, permitindo a aplicação de ligadura transfixante com ácido poliglicólico 2-0 na vagina, em posição caudal à ferida vaginal. Naqueles animais nos quais isso não foi possível (três cães), realizou-se o fechamento do defeito criado com sutura contínua simples com fio de ácido poliglicólico 2-0. Dessa forma, não foi mantida comunicação entre a luz vaginal e a cavidade pélvica. Por fỉm, a vagina foi recolocada em sua posição anatômica com o dígito do cirurgião. Obtida a desinsuflação da cavidade, a ferida do portal abdominal foi ocluída nos planos muscular e cutâneo, com fio de ácido poliglicólico 3-0 e 
mononáilon 4-0, respectivamente, em padrão isolado simples.

Para o procedimento de NOTES total (grupo GNT), as cadelas foram posicionadas em decúbito dorsal e procedeu-se à adequada antissepsia cirúrgica e lavagem da vagina conforme descrito no grupo anterior. Os animais foram submetidos à sondagem uretral, promovendo-se total esvaziamento da bexiga. Foi apreendido o fundo da vagina junto à região da cérvix, com pinças hemostáticas de Haslted. Com bisturi, realizou-se incisão da mucosa vaginal, seguida de breve dissecação da musculatura da vagina até se obter o acesso à cavidade pélvica. Na sequência, foi introduzida pela ferida vaginal uma cânula descartável e transparente de $11 \mathrm{~mm}$, a qual, por dissecção romba, promoveu a ruptura da serosa vaginal. Posteriormente, removeu-se o trocarte e, pelo orifício vaginal criado, foi introduzido endoscópio rígido com canal de trabalho de $10,5 \mathrm{~mm}$ e $30^{\circ}$ e insuflou-se a cavidade abdominal com $\mathrm{CO}_{2}$ até uma pressão de $12 \mathrm{mmHg}$, por meio da cânula. Salienta-se que o endoscópio foi introduzido pela ferida vaginal e não pela parede abdominal, como no grupo NOTES híbrida, em que se utilizou o artroscópio.

A sequência cirúrgica foi similar à descrita para o grupo de NOTES híbrida, contudo toda a instrumentação e visualização da cavidade foi obtida através da vagina, sem quaisquer punções para posicionamento de portais através da musculatura abdominal. Obtida a hemostasia e a secção de ambos os mesovários e vasos ovarianos, foram promovidos a apreensão do ligamento suspensor e o tracionamento do ovário para o interior da cânula. A hemostasia dos vasos uterinos foi realizada de forma extracavitária, por meio de ligaduras transfixantes com fio de ácido poliglicólico 2-0 envolvendo o corpo do útero, em posição caudal à ferida vaginal. Em quatro cães isso não foi possível, portanto fez-se necessária a realização de uma sutura contínua simples com fio de ácido poliglicólico 2-0 para o fechamento do defeito criado. Por fim, o coto uterino foi recolocado na sua correta posição anatômica por palpação digital e promoveu-se a desinsuflação da cavidade abdominal.

Para os três grupos, os parâmetros de $\mathrm{FC}, f$, PAS, PAD, PAM e PVC foram aferidos, com um monitor multiparamétrico, nos seguintes momentos: a) antes da medicação pré-anestésica (basal), b) após a medicação pré-anestésica, c) após a indução anestésica, d) após o início do procedimento cirúrgico, sendo aferidos a cada 15 minutos durante o transoperatório, até ocorrer a extubação orotraqueal. Os parâmetros hemogasométricos foram analisados em quatro momentos: a) antes da medicação pré-anestésica (basal), b) após a indução anestésica, c) 10 minutos após a secção do primeiro mesovário, e) logo após o término da cirurgia.

O estresse pós-operatório foi avaliado por meio da dosagem do cortisol sérico efetuada nos seguintes momentos: T0) antes da medicação pré-anestésica (basal); T1) seis horas após a extubação orotraqueal; T2) 12h após a extubação orotraqueal; e T3) $24 \mathrm{~h}$ após a extubação orotraqueal. A avaliação dolorosa foi obtida pela escala visual analógica (EVA) e pela escala de Melbourne. Essa avaliação foi realizada um dia antes do procedimento cirúrgico (basal) e duas, quatro, seis, 12, 24, 48 e 72h após a extubação orotraqueal.

Como medicação pós-operatória, instituiu-se administração de cloridrato de tramadol $(4 \mathrm{mg} / \mathrm{kg}$, SC) seis horas após a aplicação da medicação pré-anestésica, o qual foi repetido a cada oito horas, durante 72 horas pós-operatórias. Nos casos em que foram imputadas, no período pósoperatório, notas acima de $50 \mathrm{~mm}$ na escala visual analógica (EVA), foi realizada analgesia resgate com sulfato de morfina $(0,3 \mathrm{mg} / \mathrm{kg}, \mathrm{IM})$, e concluída a avaliação da dor.

Para a análise estatística, utilizou-se ANOVA, com posterior teste de Dunnet, para comparação de médias dentro de cada grupo em relação ao tempo zero. Para comparações entre os grupos, em cada momento, utilizou-se ANOVA, seguido do teste de Tukey. As diferenças foram consideradas significativas quando $\mathrm{p} \geq 0,05$.

\section{RESULTADOS E DISCUSSÃO}

Ao se comparar o tempo cirúrgico requerido para a execução da OSH nos diferentes grupos, percebe-se que este foi significativamente maior no GNH $(74,28 \pm 34,21 \mathrm{~min})$. Em relação aos demais grupos, verificaram-se médias similares de tempo substancialmente curto entre o GC $(29,28 \pm 6,47 \mathrm{~min})$ e o GNT $(30,42 \pm 7,61 \mathrm{~min})$, 
(Fig.1A). Nesse viés, ressalta-se que a execução de procedimentos videocirúrgicos em tempo similar ao procedimento convencional demonstra a adequação da técnica de NOTES total aqui executada, haja vista que a maioria das cirurgias videoassistidas despende prolongado tempo operatório, principalmente nas primeiras etapas do treinamento, conforme retratam Freeman et al. (2011) e Silva et al. (2011). O diminuto período de execução no grupo GNT em parte pode ser atribuído ao fato de a hemostasia dos pedículos ovarianos e do útero ter sido realizada por meio de coagulação bipolar com corte simultâneo, o que conferiu maior agilidade ao procedimento. Embora essa mesma técnica também tenha sido executada no grupo $\mathrm{GNH}$, a demora para adentrar o abdômen com o artroscópio e, principalmente, a dificuldade de visualização com o endoscópio de menor diâmetro que aqueles rotineiramente usados resultaram em maior gasto de tempo. Além disso, no GNT o cirurgião e o câmera já se apresentavam treinados na execução conjunta do procedimento, o que acabou não ocorrendo no GNH.

Considerando-se os dois grupos de cirurgia endoscópica por orifícios naturais (NOTES), a etapa que consumiu maior tempo cirúrgico foi durante a exteriorização do corno uterino pela ferida vaginal. Outro detalhe quanto a esse acesso, tanto na forma híbrida como na forma pura, é a sua dificuldade de execução em cadelas adultas de grande porte, as quais possuem canal vaginal longo. Essa característica do acesso transvaginal difere das condições observadas na OSH por videolaparoscopia convencional, na qual a hemostasia dos pedículos ovarianos e a do corpo uterino podem se configurar como os momentos cirúrgicos que resultaram em maior dificuldade técnica (Malm et al., 2004), nos quais, ao se empregarem clipes hemostáticos de titânio, consome-se considerável tempo operatório.

No que tange às análises efetuadas no período transoperatório, percebe-se que, após a MPA, os cães do GNH apresentaram frequências cardíacas (FC) mais elevadas $(119,42 \mathrm{bpm} \pm 26,96)$ que os cães dos demais grupos (GC: 84,28bpm $\pm 21,35$; GNT: 90,85bpm \pm 14,36). Após a indução anestésica e no transcorrer do procedimento cirúrgico, entretanto, não houve diferenças significativas nos valores da FC e da frequência respiratória $(f)$ entre os diferentes grupos. Em relação às avaliações das pressões arteriais, observa-se diminuição significativa nas PAD e PAM aos 15 e 30 minutos transoperatórios nos dois grupos de cirurgia por NOTES (PAD-GNT15min: $67 \mathrm{mmHg} \pm 14,07$;

PAD-GNH15min: $\quad 73,42 \mathrm{mmHg} \pm 11,60$;

PAD-GNT30min: $\quad 66,71 \mathrm{mmHg} \pm 9,55$;

PAD-GNH30min: $\quad 68,14 \mathrm{mmHg} \pm 13,33$;

PAM-GNT15min: $\quad 81,14 \mathrm{mmHg} \pm 14,92$;

PAM-GNH15min: $88,71 \mathrm{mmHg} \pm 14,81$; PAM

- GNT30min: $\quad 80,42 \mathrm{mmHg} \pm 9,18$; PAM -

GNH30min: $\quad 84,28 \mathrm{mmHg} \pm 16,32$ ), em

comparação com a técnica convencional

(PAD-GC15min: $\quad 96,57 \mathrm{mmHg} \pm 19,58$;

PAD-GC30min: $\quad 89,71 \mathrm{mmHg} \pm 13,99$;

PAM-GC15min: $109,28 \mathrm{mmHg} \pm 21,96$;

PAM-GC30min: $103,71 \mathrm{mmHg} \pm 15,64)$

(Fig. 1B e 1C). A respeito dos valores de PAS analisados, não foram verificadas diferenças significativas entre os grupos testados.

Essas diminuições nas pressões arteriais médias e diastólicas encontradas nos grupos de OSH via NOTES são atribuídas ao pneumoperitônio, que ocasiona aumento na pressão intra-abdominal (PIA), e ao acúmulo de $\mathrm{CO}_{2}$ na corrente sanguínea. Tais alterações contribuem para o aumento da resistência vascular sistêmica e a compressão das artérias e veias abdominais, resultando em diminuição do retorno venoso, do débito cardíaco e, consequentemente, nas pressões arteriais, conforme descrevem Pedroso et al. (2007). Para Oliveira (2005), até mesmo pequenos valores de PIA $(10 \mathrm{mmHg})$ originam diminuição no débito cardíaco, e, quando estão acima de $22 \mathrm{mmHg}$, a pré-carga encontra-se diminuída em até $80 \%$ dos pacientes humanos normovolêmicos. Entretanto, mesmo com a considerável diminuição nas pressões arteriais durante a execução das técnicas de NOTES, esses parâmetros ainda estavam dentro dos limites fisiológicos defendidos por Conceição $e t$ al. (2005) e, assim, não comprometem a exequibilidade segura dos procedimentos.

Apesar de Botter et al. (2005) afirmarem que a instalação do pneumoperitônio em procedimentos videocirúrgicos pode resultar em comprometimento de retorno venoso e, consequentemente, em aumento da PVC, esses dados não foram encontrados no presente estudo e até mesmo se confrontaram com os disponíveis na literatura, haja vista que os valores de PVC 
foram significativamente maiores no grupo de OSH convencional nos momentos antes da MPA (PVC-GC: $16,57 \mathrm{cmH}_{2} \mathrm{O} \pm 10,9$; PVC-GNT: $11 \mathrm{cmH}_{2} \mathrm{O} \pm 2,51$; PVC-GNH: 7,28cmH $\mathrm{cm}_{2} \mathrm{O} 3,68$ ), após a MPA (PVC-GC:10 $\mathrm{cmH}_{2} \mathrm{O} \pm 1,52$; PVC-GNT: $\quad 8,86 \mathrm{cmH}_{2} \mathrm{O} \pm 3,84$; PVC-GNH: $\left.4,28 \mathrm{cmH}_{2} \mathrm{O} \pm 2,75\right)$ e após a incisão abdominal (PVC-GC:19 $\mathrm{cmH}_{2} \mathrm{O} \pm 10,13$; PVC-GNT: $8,14 \mathrm{cmH}_{2} \mathrm{O} \pm 3,48 ; \quad$ PVC-GNH: $\quad 10,57 \mathrm{cmH}_{2} \mathrm{O} \pm 6,47$ ) (Fig. 1D). Isso ocorreu pelo simples fato de os cães utilizados nesse grupo apresentarem valores basais (antes da MPA) já elevados $\left(16,57 \mathrm{cmH}_{2} \mathrm{O} \pm 10,9\right)$, evoluindo, dessa mesma maneira, nos demais momentos. Ressalta-se que, na presente pesquisa, foram encontrados valores fisiológicos de PVC superiores aos defendidos por Walton (1998), que afirma que tais parâmetros em cães e gatos podem situar-se entre -2 e $10 \mathrm{cmH}_{2} \mathrm{O}$.

Levando-se em consideração os valores dos gases sanguíneos obtidos dentro de cada grupo, verificou-se diminuição significativa de $\mathrm{pH}$, aumento de $\mathrm{PaCO}_{2}$, diminuição de $\mathrm{PaO}_{2}$ e aumento de $\mathrm{HCO}_{3}, 10$ minutos após a secção do primeiro mesovário e logo após o término da intervenção cirúrgica, em todos os grupos experimentais. Esses dados permitem afirmar que, em todos os grupos, ocorreu acidose respiratória. De outra parte, comparando-se os valores de gases sanguíneos entre os grupos, ocorreu diminuição significativa do $\mathrm{pH}$, aumento de $\mathrm{PaCO}_{2}$, e diminuição de $\mathrm{PaO}_{2}$ aos 10 minutos após a secção do primeiro mesovário no grupo de NOTES híbrida (GNH) (Fig. 2A, 2B e 2C), ou seja, a acidose respiratória desenvolvida no grupo $\mathrm{GNH}$ reveste-se de maior gravidade em relação aos demais. Somando-se a isso, evidenciou-se aumento significativo da $\mathrm{EtCO}_{2}$ aos 15 e $30 \mathrm{~min}$ transoperatórios nesse mesmo grupo $\left(\mathrm{EtCO}_{2}-\mathrm{GNH} 15 \mathrm{~min}: 48,14 \mathrm{mmHg} \pm 7,42 ; \quad \mathrm{EtCO}_{2-}\right.$ GNH30min:49,43mmHg $\pm 5,62$ ) em comparação ao $\mathrm{GC} \quad\left(\mathrm{EtCO}_{2}-\mathrm{GC} 15 \mathrm{~min}: 38,85 \mathrm{mmHg} \pm 4,45\right.$; $\left.\mathrm{EtCO}_{2}-\mathrm{GC} 30 \mathrm{~min}: 41 \mathrm{mmHg} \pm 3,94\right)$ e ao GNT $\left(\mathrm{EtCO}_{2}-\mathrm{GNT} 15 \mathrm{~min}: 40 \mathrm{mmHg} \pm 4,93 ; \quad \mathrm{EtCO}_{2}-\right.$ GNT30min:40,28mmHg $\pm 4,64$ ) (Fig. 2D), fato que confirma a ocorrência de elevados valores de $\mathrm{PaCO}_{2}$, causadores da acidemia.

Conforme Lemos et al. (2003), a acidose e a hipercapnia nos procedimentos videocirúrgicos decorrem principalmente da absorção de $\mathrm{CO}_{2}$ pela cavidade peritoneal, o qual é absorvido pela circulação venosa e eliminado pelos pulmões. No entanto, apesar de tal experimento avaliar duas técnicas videoassistidas, apenas a do grupo NOTES híbrida desenvolveu acidose severa. Acredita-se que isso possa ser atribuído ao seu maior tempo operatório, o que conduziu à maior exposição ao $\mathrm{CO}_{2}$, haja vista que, de acordo com Botter et al. (2005), a magnitude da acidose está relacionada com o tempo de duração da distensão abdominal.

Em relação à avaliação da dor realizada no presente experimento, verificou-se, durante $\mathrm{o}$ transoperatório, que dois animais do grupo de OSH convencional (GC) demonstraram elevação de FC e PAS acima de $20 \%$ do valor basal, sendo necessário instituir analgesia resgate no transoperatório com sulfato de fentanila, fato que não ocorreu nos demais grupos avaliados. Isso advoga quanto ao maior estímulo doloroso que o procedimento aberto ocasiona no período transcirúrgico, talvez pela maior exposição tecidual e manipulação visceral, contudo também não se pode descartar possível estímulo associado à maior lesão parietal de acesso, incluindo até mesmo o uso de afastadores durante determinadas etapas do procedimento.

Somam-se a isso os dados adquiridos da avaliação dolorosa no período pós-operatório, em que todos os cães pertencentes ao grupo aberto (GC) necessitaram de analgesia resgate com sulfato de morfina às duas (cinco cães) ou quatro horas (dois cães) pós-operatórias. Em contraste, no grupo de NOTES total (GNT), nenhum dos animais necessitou de analgesia resgate durante as 72 horas de avaliação pós-operatória. Nesse mesmo sentido, no grupo de NOTES híbrida $(\mathrm{GNH})$, apenas dois dos sete cães avaliados necessitaram de complementação analgésica de morfina duas horas pós-operatórias. Esses dados confirmam a ocorrência de menor dor póscirúrgica nas intervenções de mínima invasão, corroborando Dapri (2010), o qual defende que as técnicas de cirurgias endoscópicas por orifícios naturais são mais benéficas devido à reduzida necessidade de analgésicos no controle da dor. Além disso, é fato que a extensão da lesão na parede abdominal reflete diretamente na intensidade da dor e na recuperação pósoperatória, haja vista que o grupo convencional foi intensamente mais doloroso, seguido do grupo de NOTES híbrida, e quase impercebível na técnica de NOTES total, a qual não envolve 
qualquer lesão na parede abdominal. Ressalta-se também que o fato de a técnica de NOTES híbrida ter exigido maior tempo de execução pode estar diretamente ligado à maior manipulação e, consequentemente, à maior dor nesse grupo do que no grupo NOTES total.

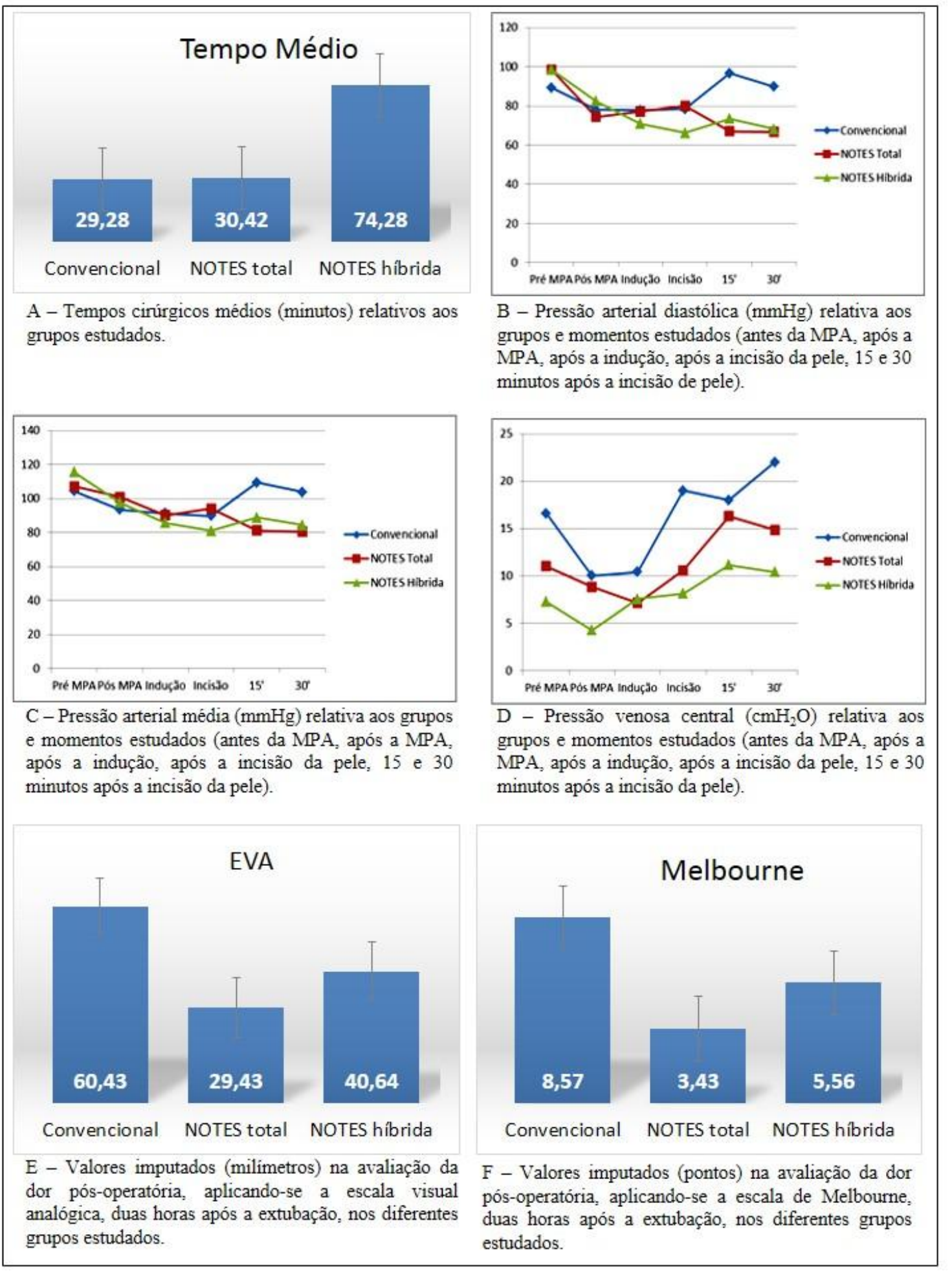


Figura 1 - Gráficos referentes aos resultados de parâmetros trans e pós-operatórios. (A) tempo cirúrgico; (B) pressão arterial diastólica; (C) pressão arterial média; (D) pressão venosa central; (E) escala visual analógica; (F) escala de Melbourne.

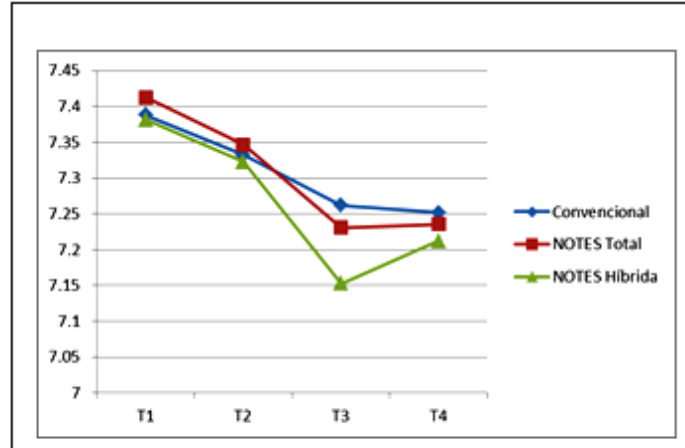

A - PH arterial relativo aos grupos e momentos estudados.

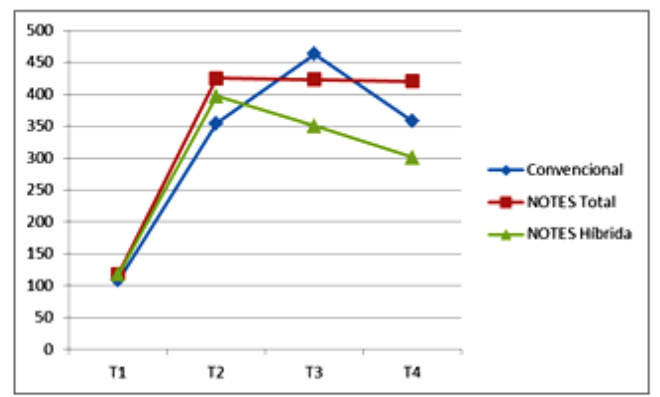

C - Pressão parcial de oxigênio no sangue arterial (mmHg) relativa aos grupos e momentos estudados.

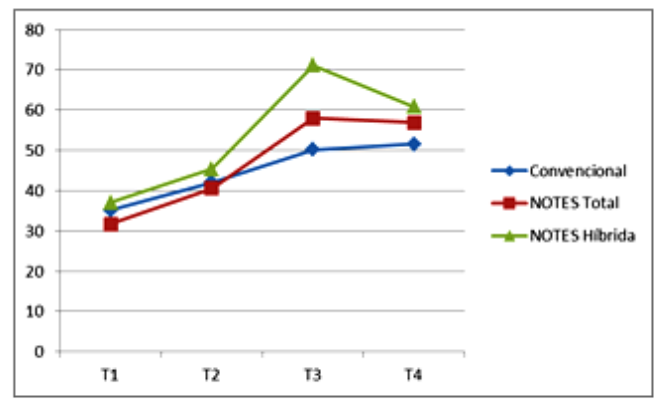

B - Pressão parcial de dióxido de carbono no sangue arterial (mmHg) relativa aos grupos e momentos estudados.

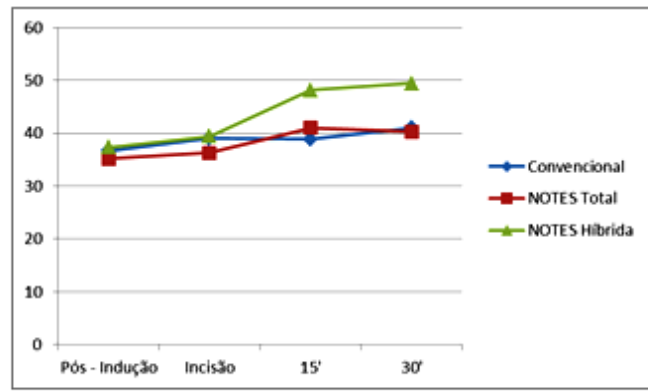

D - Concentração expirada de dióxido de carbono $\left(\mathrm{ETCO}_{2}\right)(\mathrm{mmHg})$ relativa aos grupos e momentos estudados (após a indução, após a incisão da pele, 15 e 30 minutos após a incisão de pele).

Figura 2. Gráficos referentes aos parâmetros hemogasométricos e da concentração expirada de dióxido de carbono. (A) pH arterial; (B) pressão parcial de dióxido de carbono; (C) pressão parcial de oxigênio; (D) concentração expirada de dióxido de carbono.

Nesse sentido, comparando-se estatisticamente os valores imputados na EVA e na escala de Melbourne nas primeiras duas horas pós-operatórias, percebe-se que o grupo convencional (GC) apresentou valores significativamente mais elevados que os demais grupos (EVA-GC: 60,43mm $\pm 12,94$; EVA-GNT: 29,43mm $\pm 5,04$; EVA-GNH: 40,64mm $\pm 13,62$; Melbourne-GC: $8,57 \pm 1,81$; MelbourneGNT:3,43 $\pm 2,99$; Melbourne:GNH: 5,56 $\pm 1,21$ ), o que confirma matematicamente menores escores de dor nos procedimentos via NOTES (Fig. 1E e1F). Esses dados também são condizentes com os encontrados por Freeman et al. (2010), os quais verificaram que as cadelas submetidas à ooferectomia por NOTES transgástrica demonstraram menor evidência de dor ao serem comparadas com o procedimento aberto e laparoscópico. Assim, os dados encontrados neste experimento permitem afirmar que os procedimentos abertos (via técnica convencional) são significativamente mais invasivos e dolorosos que os procedimentos por NOTES.

Cabe ressaltar que, no presente trabalho, objetivou-se ampliar a avaliação da dor por meio da dosagem sérica de cortisol, entretanto não se evidenciaram alterações significativas quanto a esse marcador. É pertinente lembrar a dificuldade de excluir outras causas de estresse envolvidos, incluindo a mudança de recinto e a resposta orgânica à anestesia e à cirurgia, 
independentemente de sua maior ou menor extensão. Ainda que Zanella et al. (2009) coloquem o cortisol plasmático como bom indicador de estresse trans e pós-operatório, na presente pesquisa os cães já apresentavam valores bem acima do basal em todos os grupos, antes mesmo de serem submetidos ao procedimento cirúrgico.

\section{CONCLUSÃO}

A técnica de OSH por NOTES total apresenta parâmetros cardiorrespiratórios, pressóricos e hemogasométricos semelhantes à técnica convencional e mais estáveis que a técnica de NOTES híbrida executada com artroscópio de $2,7 \mathrm{~mm}$. Ambas as técnicas de NOTES resultam em menor dor trans e pós-operatória quando comparadas com a técnica convencional.

\section{REFERÊNCIAS}

BERGMAN, S.; MELVIN, S. Natural orifice translumenal endoscopic surgery. Surg. Clin. North. Am., v.88, p.1131-1148, 2008.

BOTTER, F.C.S.; TAHA, M.O.; FAGUNDES, D.J. et al. O papel do penumoperitônio na avaliação de parâmetros respiratórios e hemodinâmicos de ratos anestesiados, com ou sem intubação intratraqueal. Rev. Col. Bras. Cir., v.32, p.261-266, 2005.

BRUN, M.V.; SILVA, M.A.M.; MARIANO, M.B. et al. Ovariohysterectomy in a dog by a hibrid NOTES technique - a case report. Can. Vet. J., v.52, p.637-640, 2011.

CONCEIÇÃO, E.D.V.; NISHIMORI, C.T.; MORAES, P.C. et al. Parâmetros eletrocardiográficos e cardiovasculares em cães anestesiados com isofluorano e submetidos à hipovolemia aguda. Cienc. Rural, v.35, p.13511356, 2005.

DAPRI, G. Single access laparoscopic surgery: Complementary or alternative to NOTES? World. J. Gastrointest. Surg., v.2, p.207-209, 2010 .

FREEMAN, L.J.; CHIOREAN, M.V.; CONSTABLE, P.D. Comparison of pain and postoperative stress in dogs undergoing natural orifice transluminal endoscopic surgery, laparoscopic, and open oophorectomy. Gastrointest. Endosc., v.72, p.373-380, 2010.
FREEMAN, L.; RAHMANI, E.Y.; BURGESS, R.C.F. et al. Evaluation of the learning curve for natural orifice trasluminal Endoscopic Surgery: Bilateral ovariectomy in dogs. Vet. Surg., v.40, p.140-150, 2011.

KALLOO, A.N.; SINGH, V.K.; JAGANNATH, S.B. et al. Flexible transgastric peritoneoscopy: a novel approach to diagnostic and therapeutic interventions in the peritoneal cavity. Gastrointest. Endosc., v.60, p.114-117, 2004.

LEMOS, S.L.S.; VINHA, J.M.; SILVA, I.S. et al. Efeitos do pneumoperitônio com ar e $\mathrm{CO}_{2}$ na gasometria de suínos. Acta. Cir. Bras., v.18, p.445-451, 2003.

MALM, C.; SAVASSI-ROCHA, P.R.; GHELLER, V.A. et al. Ovário-histerectomia: estudo experimental comparativo entre as abordagens laparoscópica e aberta na espécie canina - Intraoperatória - I. Arq. Bras. Med. Vet. Zootec., v.56, p.457-466, 2004.

OLIVEIRA, C.R.D. Anestesia para cirurgia videolaparoscópica. Rev. Bras. Videocir. v.3, p.32-42, 2005

OTERO, P.E. 2005. Dor: Avaliação $e$ tratamento em pequenos animais. Interbook, São Paulo. 293p.

PEDROSO, A.M.G.; MARUBAYASHI, L.; GORI, R. et al. Aspectos relevantes da Anestesia na videocirurgia colorretal. Rev. Bras. Coloproct., v.27, p.284-287, 2007.

SHAFI, B.M.; MERY, C.M.; BINYAMIN, G. et al. Natural orifice translumenal endoscopic surgery (NOTES). Semin. Pediatr. Surg., v.15, p.251-258, 2006.

SILVA, M.A.M. Avaliação laparoscópica das aderências intraperitoneais pós-cirúrgicas em cadelas: emprego de duas doses de solução de azul de metileno a 1\% na profilaxia. 2008. 74f. Dissertação (Mestrado) - Escola de veterinária, Universidade Federal de Goiás.

SILVA, M.A.M.; BATISTA, P.A.C.S.; POGIANNI, F.M. et al. Ovário-histerectomia vídeo-assistida com único portal em cadelas: Estudo retrospectivo de 20 cães. Cienc. Rural., v.41, p.294-300, 2011. 
SILVA, M.A.M.; BRUN, M.V.; TONIOLLO, G.H. et al. Ovário-histerectomia por Notes transvaginal pura (NOTES-OHE) em uma cadela - primeiro relato de caso. In: IX Congresso Brasileiro de Cirurgia e Anestesiologia Veterinária. 2010, Búzios. Anais... Búzios, 2010.

WAGH, M.S; MERRIFIELD, B.F.; THOMPSON, C.C. 2006. Survival studies after endoscopic transgastric oophorectomy and tubectomy in porcine model. Gastrointest. Endosc., v.63, p.473-478, 2006.
WALTON, R.S. Choque. In: WINGFIELD, W.F. Segredos em Medicina Veterinária. Porto Alegre: Artes Médicas Sul. 1998. p.49-54.

ZANELLA, R.; THOMAZI, G.; GUIZZO Jr, N. et al. Cortisol plasmático como indicador de estresse em colopexias laparoscópicas com implante de tela de polipropileno em cães. Acta. Scientiae. Veterinariae, v.37, p.231-237, 2009. 